\title{
Choice of bottom-hole filter construction for viscous fluid filtration
}

\author{
Khabibullin Marat Yakhievich \\ Ufa State Petroleum Technological University, \\ Branch of the University in the City of Oktyabrsky, Russian \\ Federation \\ E-mail: m-hab@mail.ru
}

\begin{abstract}
Determination of filters resistance value with net filtering surface and block types is rather difficult mathematically. It is caused by a great amount of parameters, influencing cage filtration capacity. In net filters, depending on the type of weaving, they are different: wire diameter of the strand and the base, different diameters in horizontal and vertical planes, frame construction which is considered a unit with the net. In block constructions they are: sizes and homogeneity of particles composition, filtration cage thickness, geometry of filtration channels etc. That is why, it is better to estimate efficiency of these filters by their permeability. The most perspective are frame-filters with horizontal gaps, whose resistance and gaps interference effect are less. It should be noted that thanks to peculiarities of screen construction the inlet area is greater than in other constructions with the same minimal value of holes sizes. Recommendations on inlet area and filter gap size should take into account factors of well production rate, layer fluid viscosity, granular composition of layers, consolidation of the bottom-hole zone, clogging and bridging of the deposits.
\end{abstract}

Keywords - hydraulic, loss, resistance, inlet area, frame, block

\section{INTRODUCTION}

There is a shortcoming in extracting wells equipped with filters. This shortcoming is with the degree and character of layer formation exposing, which depends on filter construction placed in the well [1, 2]. According to [3] in calculations total filtration resistance should be divided onto peculiar, corresponding to different zones of filtration. If the well bottom-hole design does not influence flow character in the zone distant from the well, in the zone near filter and on the filter itself there are additional hydraulic losses which should be treated as dimensionless parameters, influencing total extracted fluid flow resistance.

Additional resistance according to the common flow schema is introduced as in [3]:

$$
\zeta=\zeta_{1}+\zeta_{2}
$$

where $\zeta_{1}$ and $\zeta_{2}$ are resistance conditioned by the degree and character of formation exposing. Estimation of well imperfection influence by formation exposing degree, with the account of inflow to it depending on the relation $l / m$ (where $l$ is filter length, and $m$ is total capacity of the productive formation) and the graphs for determining resistance $\zeta_{1}$ are given in [4].

\author{
Suleimanov Rustem Iskhakovich \\ Ufa State Petroleum Technological University, \\ Branch of the University in the City of Oktyabrsky, Russian \\ Federation \\ E-mail: ris2015@rambler.ru
}

Resistance $\zeta_{2}$ is a complex characteristic, depending on the quality of well completion, filter hydraulic peculiarities, conditioned by the construction, as well as filter cage clogging and break down of linear mode of filtration That is why value $\zeta_{2}$ can be determined:

$$
\zeta_{2}=\zeta_{2 \Phi}+\zeta_{2 \pi}+\zeta_{2 \pi /}
$$

where $\zeta_{2 \Phi}, \zeta_{2 \pi}, \zeta_{2 \pi /}$ are resistances determined by filter, deposits character, and deviation from linear mode of filtration.

Filtration of viscous fluid through porous media with comparatively small pores goes accourding to Darcy's linear law [5] and the value of total resistance can be determined:

$$
\zeta_{2}=\zeta_{2 \Phi}+\zeta_{2 \pi}
$$

Here we can see that filters hydraulic parameters are crucial in the choice of filter optimal constructions and their elements. They are determined by filter resistance, and when a filter functions in semi consolidated and soft formations or in gravel package contact pressure loss in filter-rock zone and sand-holding ability of the filter cage are important.

\section{MATERIALS AND METHODS}

Hydraulic parameters of a rock-filter system (at other conditions) are consequence of geometric filter cage parameters, forming mutual position of gaps and influencing flow resistance by destructing its linearity, its diffraction and so on.

Enhancing permeability of the filter caging with the same gap size by porosity increase in near-filter zone lessens losses in the filter-rock contact zone. Also, the form and mutual position of filter cage elements, influencing creating bridges of large sand fractions or gravel pack hold the particles forming layer frame with simultaneous colmatant pass.

Nowadays different filters are used. There are ones with round gaps, vertical or horizontal spills, whose length is different and can be equal to layer thickness, with filtering surface of nets, and block filters. After analyzing similar solutions suggested by M. Mason, V.I. Shurov constructed 
revised graphs of the dependence (picture 1) $\zeta_{2 \Phi}$ on the parameters for filters with round gaps [6]:

$$
\alpha=d_{0} / \text { д и } \beta=n Д \text {, }
$$

where $d_{0}$ is filter gaps diameter;

$n$ their amount per length unit;

$Д$ is filter diameter.

As parameters $\alpha$ and $\beta$ are parameters of relative inlet area, then the graph shows that with the increase of inlet area filter resistance lowers $\zeta_{2 \phi}$.

M. R. Harris theoretical investigations [7] show that total efficiency of round gaps groups to the flow coefficient depends on their mutual position. Some results are given on the graph (picture 2).

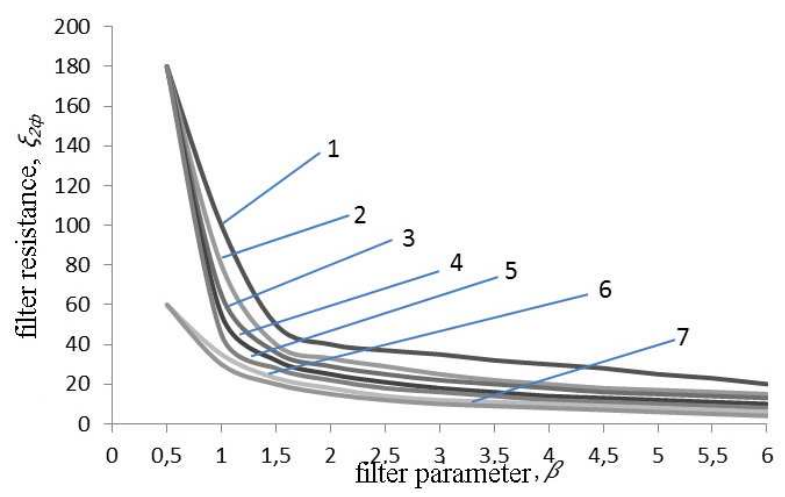

Fig. 1. Dependence graph $\boldsymbol{\zeta}_{\mathbf{2} \phi \text { on parameters }} \quad \boldsymbol{\beta}=0,01 \boldsymbol{n}$ म $_{\text {and }}$

$\boldsymbol{\alpha}$ for round gaps filters: $\quad 1-\alpha=0,03 ; 2-\alpha=0,04 ; 3-\alpha=0,05 ; 4-\alpha=0,06 ; 5-$ $\alpha=0,07 ; 6-\alpha=0,08 ; 7-\alpha=0,09$

Graphs are constructed with the account of the following conditions:

- supply contour radius is $200 \mathrm{~m}$;

- cemental ring external radius is $76 \mathrm{~mm}$;

- perforated channel length is $30,5 \mathrm{~cm}$;

- perforated channel diameter $12,7 \mathrm{~mm}$; $\mathrm{mm}$.

- perforator bullet penetration over the top cement 300

These results show there is lesser pressure change at the given expenditure when the gaps are positioned uniformly round the surface in the horizontal plane, and the pressure change is the greatest along vertical plane along one general line.
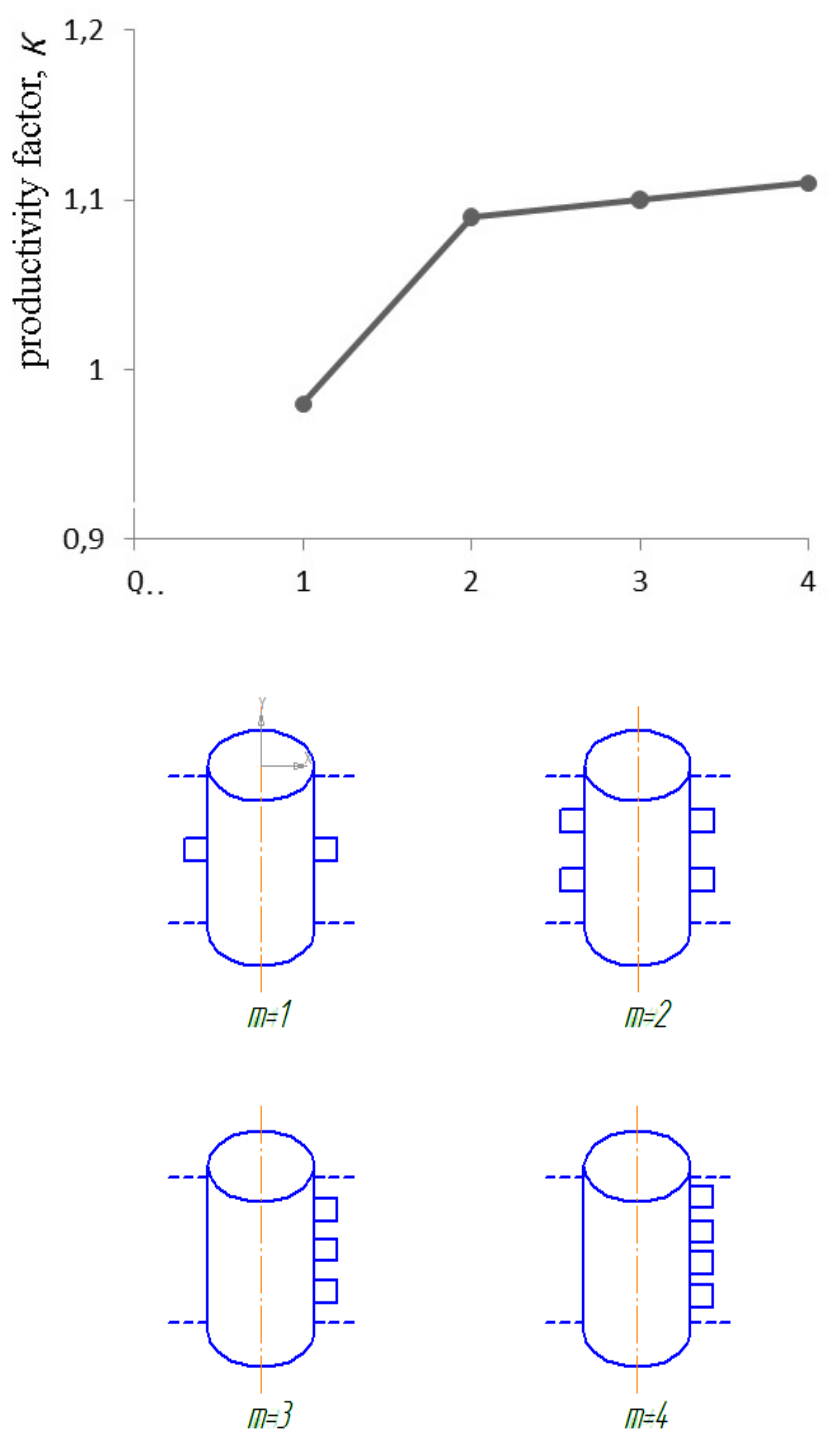

Fig. 2. Efficiency coefficient dependence $(K)$ on the perforation scheme and amount of perforations $(\mathrm{m})$ planed

Resistance values $\zeta_{2 \phi}$ for filters, whose length is equal to layer thickness, placed vertically along generating of the pipe, have rather approximate results when determine them by different methods. V.T. Cordwell and S.K. Dodson [8] suggested the expression:

$$
\zeta_{2 \Phi}=\frac{2}{n} \cdot \ln \frac{2}{\pi \eta} \text {, with } \eta=0,3
$$

where $n$ is amount of gaps; $\quad \eta$ is inlet area.

V.P. Pilatovskiy [9] received an expression of dimensionless hydraulic pressure in the form:

$$
\zeta_{2 \Phi}=\frac{4}{n} \cdot \ln \sin \frac{n^{1} \alpha}{2}
$$

where $n^{1}$ is an amount of solid plates; central angle determining the size of the spill. $\alpha-$ is a 
Graphic dependences (see. Picture 1), based on the results of formula calculation (6), allow finding value $\zeta_{2 \Phi}$ of rod frames and filter constructions similar to them.

In [10] it is proved that resistance value for filters, whose vertical spills length is restricted, can be determined by graph dependencies (picture 1). These dependences are suitable for filters with round holes. For rectangular holes interpolation to round holes can be done with the account of equivalent total area of cross section.

\section{RESULTS AND DISCUSSIONS}

Recommended radii of addition depend on relation of the pass length $l$ to its width $b$. At relation $l / b \leq 3$, it is preferable to add areally and the radius of the added hole is expressed by the dependence:

$$
r_{\text {orp }}=\sqrt{\frac{b \cdot l}{\pi}}
$$

a at $l / b>3$ (long and narrow spills):

$$
r_{\text {опр }}^{\prime}=\frac{b \cdot l}{2 \pi}
$$

That is radius is determined by the perimeter. As we can see from the graph dependences (picture 3), filter resistance with vertical spills decreases with total inlet area, as well as with spills width lessening with the same filtering inlet area.

For filters with pass holes, placed horizontally, the same solution, at relatively big values $r / d$, is given by A.L. Hein:

$$
\begin{aligned}
\zeta_{2 \Phi}= & \frac{d^{3}}{\pi^{2} r_{c} b^{2}}\left[6,835 \cdot \frac{b}{d}\left(1-\frac{b}{d}\right)-\right. \\
& \left.-2 L_{i} \cdot\left(\pi \cdot \frac{b}{d}\right)+\chi\left(\frac{b}{d} ; \frac{2 r_{c}}{d}\right)\right],
\end{aligned}
$$

where $d$ is distance between neighboring passes centers;

$b$ is pass height;

$r_{c}$ is current radius;

$\left(\frac{b}{d} ; \frac{2 r_{C}}{d}\right)$ is a tabulated function, whose values are given in [10].

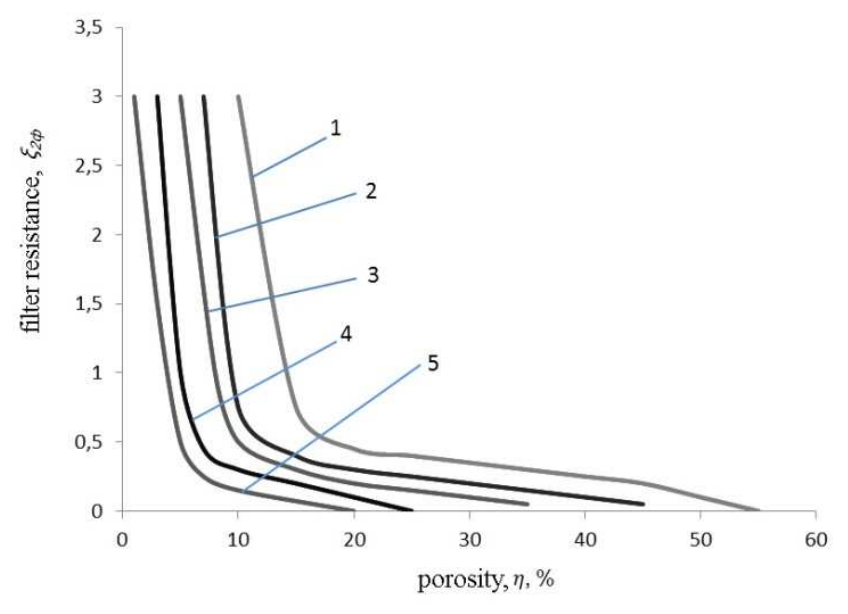

Fig. 3. Graph dependencies $\boldsymbol{\zeta}_{\mathbf{2} \Phi}$ from inlet area $\square$ for all layer thickness with spills $168 \mathrm{~mm}$ in diameter. Pass width: $1-10 \mathrm{~mm} ; 2-5 \mathrm{~mm} ; 3-3$ $\mathrm{mm} ; 4-1 \mathrm{~mm} ; 5-0,5 \mathrm{~mm}$.

In the work [11] M.N. Tikhonov gives solutions, accourding to which filter resistance value with horizontal passes is approximately $20 \%$ less, than that one of filters with cylindrical holes, shown in graph dependencies (picture 1).

Determining $\zeta_{2 \phi}$ of filters with net filtering surfaces and block filters is mathematically difficult. It is explained by large amount of parameters influencing filtration capacity of the cage. In net filters depending on the weaving - they are different wire diameter of the strand and the base, different diameters in horizontal and vertical planes, frame construction which is considered as a unit with the net. In block constructions they are sizes and homogeneity of particles composition, filtration cage thickness, geometry of filtration channels etc [12]. That is why it is better to estimate efficiency of these filters by their permeability accourding to Darcy's formula [5].

For radial filtration through ring sample:

$$
K=\frac{\mu_{\mathrm{m}} \cdot Q_{\mathrm{m}} \cdot l n \frac{r_{\mathrm{H}}}{r_{\mathrm{B}}}}{20 \cdot \pi \cdot h\left(P_{\mathrm{B}}-P_{\mathrm{B}}\right)}
$$

Where $Q_{\mathrm{f}}$ is expenditure, $\mathrm{cm}^{3} / \mathrm{s}$;

$\mu_{\mathrm{f}}$ is dynamic viscosity, MPa $\cdot \mathrm{s}$;

$P_{\mathrm{ex}}, P_{\mathrm{in}}$ is difference between external and internal surfaces pressure, MPa;

$R_{\text {ex }}, r_{\text {in }}$ are external and internal radii, $\mathrm{cm}$;

$h$ is sample height, $\mathrm{cm}$.

The formula shows permeability functionally depends on pressure difference which is determined by filter resistance $\zeta_{2 \Phi}$.

Filter hydraulics of different constructions was investigated by D. Klotz [12] and the results of filter 
permeability estimation depending on their inlet area are given in fig. 4.

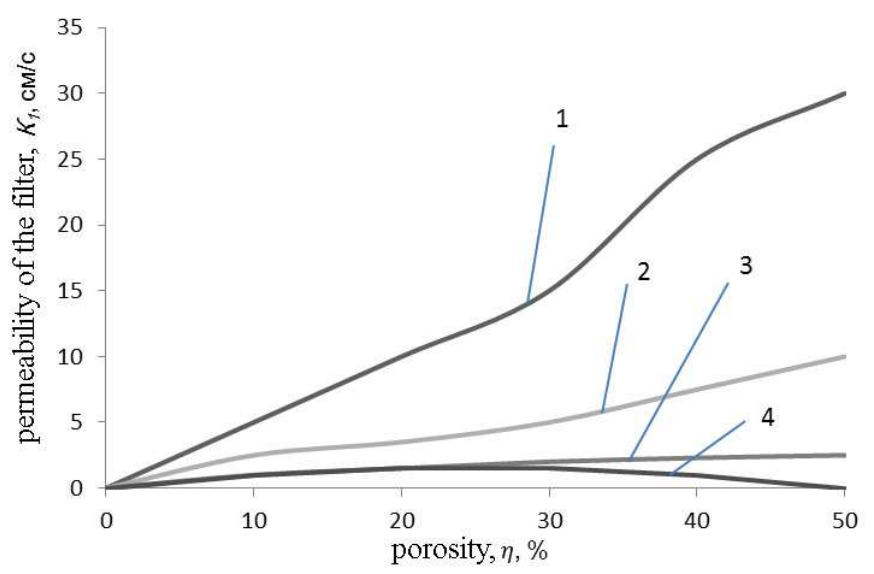

Fig. 4. Graph dependence of filter permeability on their inlet area [accourding to Klotz]: 1 - frame-wired; 2 - with bridge holes; 3 - slotted with open perforation; 4 - nets with galooned wiring.

\section{CONCLUSION}

Let's draw the conclusion:

1. Formation fluid production rate increases with filter inlet area increase.

2. Filter resistance at constant inlet area increases with lessening of its holes size.

3. Filter resistance with different perforation is nearly the same if the inlet area is similar.

4. Small vertical holes interference is greater than those of horizontal ones placed at the same distance along the parallel that is why total expenditure through filters with horizontal holes is $20 . .30 \% \%$ greater

As we can see, filters-frames with horizontal spills with less resistance and holes interference are more perspective. It should be noted that thanks to peculiarities of frame-rod filter construction greater inlet area is fulfilled than in other constructions, with the same minimal size of holes.

Recommendations on the choice of inlet area and holes size should take into account well production rate, layer fluid viscosity, layer granular composition, degree of consolidation of the near-bottom zone, clogging and arching of the rock. These parameters as well as filter-rock contact losses can be determined only experimentally on laboratory or full-scale models.

\section{References}

[1] M.Ya. Khabibullin, R.I. Suleimanov, D.I. Sidorkin, I.G. Arslanov, Parameters of damping of vibrations of tubing string in the operation of bottomhole pulse devices, Chemical and Petroleum Engineering, Vol. 53, № 5-6, pp. 378-384, 2017.

[2] M.Ya. Habibullin, , D.I. Sidorkin, Determination of tubing string vibration parameters under pulsed injection of fluids into the well, SOCAR Proceedings, № 3, pp. 27-32, 2016.

[3] M.V. Goryunova, L.S. Kuleshova, A.I. Khakimova, "Application of signal analysis for diagnostics," International Conference on Industrial Engineering, Applications and Manufacturing (ICIEAM) (Saint Petersburg: IEEE), 2017, pp. 1-5. DOI:
10.1109/ICIEAM.2017.8076487.

[4] G. A. Korn, T. M. Korn, Mathematical Handbook for Scientists and Engineers: Definitions, Theorems, and Formulas for Reference and Review, Moscow, Nauka, 1984.

[5] A. Davletbaev, V. Kireev, L. Kovaleva, A. Zainullin, R. Minnigalimov, Cold heavy oil production and production by radio-frequency electromagnetic radiation: Comparative numerical study, AIP Conference Proceedings: International Conference of Computational Methods in Sciences and Engineering 2016, ICCMSE 2016 (Athens, 17-20 March 2016), Athens: American Institute of Physics Inc., Vol. 1790, pp. 150021, 2016. DOI: 10.1063/1.4968760.

[6] Nsoga Valjacques Nyemb, Hona Jacques, Pemha Elkana, Numerical Simulation of Heat Distribution with Temperature-Dependent Thermal Conductivity in a Two-Dimensional Liquid Flow, International Journal of nonlinear sciences and numerical simulation, Vol. 18, Issue 6, pp. 507-513, 2017.

[7] A. Yu. Zaichenko, S. V. Glazov, E. A. Salgansky, Filtration combustion of viscous hydrocarbon liquids, Theoretical foundations of chemical engineering, Vol. 51, Issue 5, pp. 673-679, 2017.

[8] R.M. Shaidullina, A.F. Amirov, V.S. Muhametshin, and K.T. Tyncherov, "Designing economic socialization system in the educational process of technological university," European Journal of Contemporary Education, Vol. 6 (1), pp. 149-158, 2017. DOI: 10.13187/ejced.2017.1.1494.

[9] Heuzeroth Fabian, Fritzsche Jorg, Werzner Eric, Viscous force - An important parameter for the modeling of deep bed filtration in liquid media, Powder technology, Vol. 283, pp. 190-198, 2015.

[10] V.N. Polyakov, Yu.V. Zeigman, Yu.A. Kotenev, V.V. Mukhametshin, Sh.Kh. Sultanov, and A.P. Chizhov, "System solution for technological problems of well construction completion," (in Russian), Nanotechnologies in Construction, vol. 10-1, pp. 72-87, 2018. DOI: 10.15828/2075-8545-2018-10-1-72-87.

[11] Meirmanov Anvarbek, Nekrasova Irina, Mathematical models of a hydraulic shock, Journal of mathematical analysis and applications, Vol. 408, Issue 1, pp. 76-90, 2013.

[12] S. Dawar, G. G. Chase, Correlations for transverse motion of liquid drops on fibers, Separation and purification technology, Vol. 72, Issue 3, pp. 282-287, 2010. 